\title{
A prospective randomized cohort study on 3D-printed artificial vertebral body in single-level anterior cervical corpectomy for cervical spondylotic myelopathy
}

\author{
Feng Wei", Nanfang Xu\#, Zihe Li, Hong Cai, Feifei Zhou, Jun Yang, Miao Yu, Xiaoguang Liu, Yu Sun, \\ Ke Zhang, Shengfa Pan, Fengliang Wu, Zhongjun Liu \\ Department of Orthopedics, Peking University Third Hospital, Beijing, China \\ Contributions: (I) Conception and design: Z Liu, F Wei, H Cai; (II) Administrative support: X Liu, K Zhang; (III) Provision of study materials or \\ patients: F Zhou, M Yu, S Pan, F Wu; (IV) Collection and assembly of data: N Xu, Z Li, J Yang; (V) Data analysis and interpretation: F Wei, N Xu; (VI) \\ Manuscript writing: All authors; (VII) Final approval of manuscript: All authors. \\ \#These authors contributed equally to this work. \\ Correspondence to: Zhongjun Liu. Department of Orthopedics, Peking University Third Hospital, 49 Huayuan North Road, Beijing, China. \\ Email: puthliuzhongjun@163.com.
}

Background: This was a prospective randomized cohort study aiming at examining the safety and efficacy of artificial vertebral body (AVB) fabricated by electron beam melting (EBM) in comparison to conventional titanium mesh cage (TMC) used in single-level anterior cervical corpectomy and fusion (SL-ACCF).

Methods: Forty patients with cervical spondylotic myelopathy (CSM) underwent SL-ACCF using either the EBM-AVB or the TMC. Patients were evaluated for their demographics, radiological characteristics, neurologic function [using the Japanese Orthopaedic Association (JOA) scale], and health-related quality-oflife (HRQoL) aspects [using the Short Form 36 (SF-36)] before and after the surgery and comparison was made between the two groups both at baseline and the last follow-up. The Student t-text, paired-sample t-text, and Fisher's exact test were used when appropriate to detect any statistical significance at the level of $\alpha=0.05$.

Results: Post-operative recovery was uneventful for all patients and no revision surgery was required. There were no significant differences between the EBM-AVB group and the TMC group at baseline. Patients in both groups demonstrated significant improvement in cervical alignment, JOA score, and SF36 score after the surgery. Six months post-operatively, patients in the EBM-AVB group were found to have significantly less loss of fusion height and lower incidence for severe implant subsidence compared with the TMC group. Patients in the two groups were comparable at the last follow-up regarding their rate of fusion, cervical alignment, JOA recovery rate, SF-36 score, and by Odom's criteria.

Conclusions: For CSM patients undergoing SL-ACCF, the EBM-AVB group demonstrated comparable outcomes regarding patient cervical alignment, neurologic function, and HRQoL in comparison with the TMC group. Furthermore, the use of EBM-AVB was associated with decreased loss of the height of the fusion mass and a lower rate for severe implant subsidence.

Keywords: 3D printing; anterior cervical corpectomy and fusion (ACCF); cervical spondylotic myelopathy (CSM); Artificial vertebral body (AVB); titanium mesh cage

Submitted Dec 28, 2019. Accepted for publication Jul 09, 2020.

doi: 10.21037/atm-19-4719

View this article at: http://dx.doi.org/10.21037/atm-19-4719 


\section{Introduction}

Cervical spondylotic myelopathy (CSM) is the most common cause of spinal cord dysfunction in individuals older than 55 years (1) and can occur in $10-15 \%$ of all patients with cervical spondylosis. Patients typically present with sensorimotor dysfunction in the extremities and disturbances in sphincter function (2). Patients with moderate to severe symptoms are unlikely to experience regression of myelopathy without surgical interventions. Different surgical techniques have been evaluated in the literature in recent years (3-5), and both the anterior and the posterior approaches were found effective in preventing neurological deterioration and promoting functional recovery, when appropriately indicated. Anterior cervical corpectomy and fusion (ACCF) is an important technique when the anterior approach is desired yet spinal cord compression cannot be adequately addressed with discectomy alone. Structural autograft is the gold standard for reconstruction of the anterior spinal column following ACCF; however, complications associated with bone graft harvesting including infection, hematoma formation, fracture, pain and morbidity have been reported.

Titanium mesh cage (TMC) is a widely-used alternative in restoring anterior column height. While donor site complications are avoided, mismatch between the Young's modulus of the implant and the host bone can lead to a stress shielding effect that eventually causes subsidence (6), which is frequently observed in the early post-operative period and associated with neck pain, neurologic deterioration, and instrumentation failure (7-11). Risk factors for implant subsidence include gender, age, BMD, implant type, techniques for endplate preparation, less contact area between the implant and the endplates, sagittal mal-alignment, resection of the posterior longitudinal ligament (PLL), and intervertebral over-distraction (12-20).

Yang et al. $(21,22)$ previously introduced a 3D-printed artificial vertebral body (AVB) fabricated by electron beam melting (EBM) in sheep and found that its mechanical properties, thanks to its porosity, were comparable to cancellous bone and stress shielding effect could therefore be minimized. Additionally, the porous ultra-structure of might also be advantageous for osteo-induction (23). In this prospective randomized trial, we aimed to investigate the in vivo safety and efficacy of EBM-AVB in comparison to TMC used in patients undergoing single-level ACCF (SL-ACCF) for CSM. We present the following article in accordance with the CONSORT reporting checklist (available at http://dx.doi.org/10.21037/atm-19-4719).

\section{Methods}

\section{$E B M-A V B$}

The EBM-AVB (Aikang, China) was fabricated following protocols previously established (21), in which melted titanium alloy powder (Ti6Al4V, particle size 45-100 $\mu \mathrm{m}$ ) was used to fabricate an AVB in a layer-by-layer fashion using the EBM S12 system (Arcam AB, Sweden), according to computer-aided design (CAD) models with customization for the specific anatomical features of each patient. Several studies have confirmed the bio-compatibility of Ti6Al4V (24-27). The porosity of the EBM-AVB is $71 \%$. The EBM-AVB was designed with a $4^{\circ}$ tilted slope at each end (Figure 1) because the normal cervical lordosis between C3-7 on average was between $30-40^{\circ}$. Following a subaxial SL-ACCF, an AVB with an $8^{\circ}$ lordosis would most likely help restore the normal segmental alignment while approximating the anatomical endplate slope at the same time (compared to a flat-end design).

\section{Study design}

This prospective randomized open-label trial was conducted between January 2016 and September 2016 at a tertiary spine care center and under an investigational device exemption granted by local hospital ethics committee of Peking University Third Hospital (No. M2018206) and informed consent was taken from all participants regarding the aims and protocols of the study. The primary hypothesis was non-inferiority regarding the safety and efficacy of the investigational group against the control group and the design was approved by the institutional review board. Patients were recruited and allocated into either group according to a computerized randomization scheme. All patients received standard-of-care pre-operative assessment and a decision and plan for surgery was made by senior spine surgeons blinded to patient allocation results. Radiographic evaluation consisted of antero-posterior (AP) and lateral X-rays and magnetic resonance imaging (MRI) for enhanced soft tissue contrast.

\section{Inclusion criteria}

Inclusion criteria were: (I) diagnosis of cervical myelopathy secondary to degenerative spondylosis, migrated cervical 

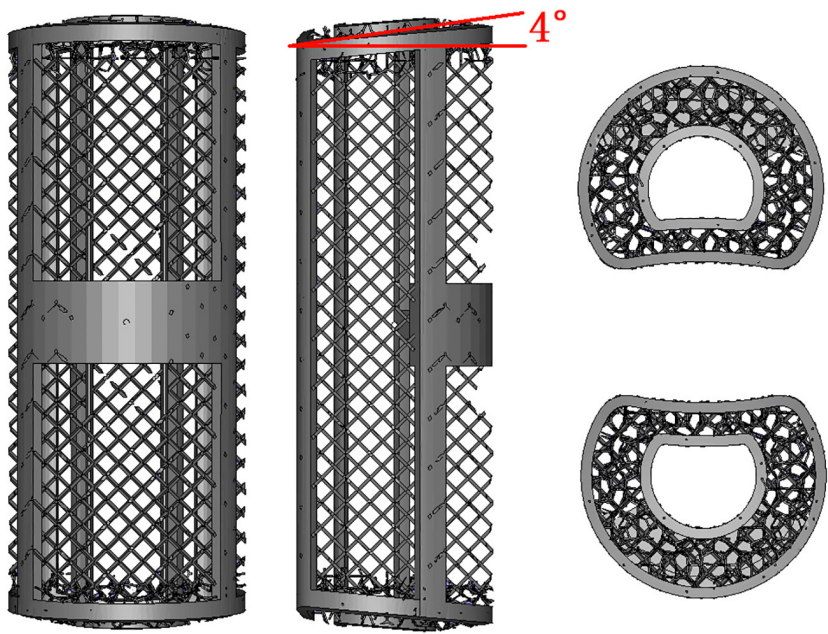

Figure 1 The AVB made with EBM was designed with a $4^{\circ}$ tilted slope at each end.

disc herniation, or ossification of the posterior longitudinal ligament (OPLL); (II) indications for SL-ACCF; (III) at least 18 years of age; (IV) willingness to participate in this study. Exclusion criteria were composed of: (I) T-score of less than -1.1 on bone densitometry; (II) cervical myelopathy associated with other conditions, such as ankylosing spondylitis, rheumatoid spondylitis, traumatic etiologies, congenital deformities, tumor, and tuberculosis; (III) medical comorbidities resulting in inability to withstand operative intervention.

\section{Surgical procedure}

All procedures were performed by the same group of spine surgeons who were blinded to patient assignment till the point of implant placement. Under general endotracheal anesthesia, a right-sided Smith-Robinson approach was adopted for exposure. The symptomatic level was identified under fluoroscopy, followed by discectomy at the cephalad and caudal intervertebral levels and corpectomy of the medial three-fifths of the vertebral body. The PLL was resected in all cases. Either an AVB or a TMC (according to the randomization scheme) was inserted under sustained distraction $(2-3 \mathrm{~mm})$ between the cephalad and caudal vertebrae for reconstruction and local bone autograft from corpectomy was used in both cases. Finally, a semiconstrained cervical plate (CSLP, Depuy-Synthes, US) was used to secure the implant. A soft cervical collar was used for 2 weeks for all patients following the surgery.

\section{Assessment of radiographic outcomes}

Patients were followed with radiographic evaluation 6 months post-operatively to assess for implant subsidence, cervical sagittal alignment, and fusion status. Subsidence was defined as a loss of any height of the fusion segments on follow-up lateral radiographs compared with the immediate post-operative radiographs. The height was measured at the center on the anterior edge of adjacent endplates. Severe subsidence was defined as a loss of height $\geq 3 \mathrm{~mm}$. Cervical sagittal alignment was evaluated as the Cobb angles between C2 and C7 (28). Criteria for fusion included mature bony trabecular bridge between the implant and the adjacent vertebrae, absence of peri-implant radiolucency, and less than $4^{\circ}$ of Cobb angle variation of the adjacent endplates (29) on dynamic lateral radiographs. In cases where dynamic radiographs were insufficient to determine fusion status, computed tomography (CT) was performed (30) to provide a more definitive evaluation.

\section{Assessment of clinical outcomes}

The Japanese Orthopaedic Association (JOA) scale, the JOA recovery rate (31), the Short Form 36 (SF-36), and the Odom's criteria (32) were used as the primary measures for clinical outcomes and were available for all patients both before the surgery and at the last follow-up.

\section{Statistical analysis}

For comparing continuous measurements such as loss of fusion height, JOA recovery rate, changes in SF-36 scores, etc., the Student $t$-text and the paired-sample $t$-text were performed when appropriated. For comparing categorical outcomes, including rates of severe implant subsidence and Odom's criteria responses, Fisher's exact test was used. Normality of data was assumed when appropriate and statistical significance level was set at 0.05 . Data were analyzed using the SPSS statistical software, version 17.0 (SPSS Inc., Chicago, IL).

\section{Results}

\section{Patient characteristics}

Forty patients consented to participate in this study. There were 20 patients ( 14 men and 6 women) in the EBM-AVB group (55.2 \pm 11.4 years; range, $31-76$ years) and 20 patients (11 men and 9 women) in the TMC group $(53.8 \pm 7.8$ years; 


\section{Page 4 of 9}

Table 1 Patient characteristics at baseline

\begin{tabular}{lccc}
\hline Characteristics & EBM-AVB group & TMC group & P value \\
\hline No. of patients & 20 & 20 & NA \\
Age, years & & & 0.675 \\
Mean \pm SD & $55.2 \pm 11.4$ & $53.8 \pm 7.8$ & \\
Range & $31-76$ & $37-64$ & \\
Gender & & & 0.327 \\
Male & 14 & 11 & \\
Female & 6 & 9 & \\
BMI, kg/m & $25.4 \pm 2.8$ & $26.8 \pm 3.7$ & 0.090 \\
Level of & & & 0.700 \\
corpectomy & & & \\
C4 & 3 & 10 & \\
C5 & 8 & 8 & \\
C6 & 8 & 0 & \\
C7 & 1 & & \\
\hline
\end{tabular}

EBM-AVB, electron beam melting-artificial vertebral body; TMC, titanium mesh cage; NA, not applicable.

Table 2 Radiological evaluation on the EBM-AVB group vs. the TMC group

\begin{tabular}{lccc}
\hline Radiological evaluation & $\begin{array}{c}\text { EBM-AVB } \\
\text { group }\end{array}$ & TMC group & P value \\
\hline Rate of fusion & $20 / 20(100 \%)$ & $19 / 20(95 \%)$ & 0.995 \\
Loss of height of the fusion segments & & \\
Mean \pm SD & $1.39 \pm 1.05$ & $2.39 \pm 1.68$ & 0.015 \\
Rate of severe subsidence & $1 / 20(5 \%)$ & $7 / 20(35 \%)$ & 0.018 \\
Global lordosis (C2-7) & & & \\
Pre-operative & $13.8 \pm 8.8$ & $16.3 \pm 9.5$ & 0.196 \\
6-month f/u & $17.9 \pm 5.0$ & $20.4 \pm 8.5$ & 0.136 \\
\hline
\end{tabular}

EBM-AVB, electron beam melting-artificial vertebral body; TMC, titanium mesh cage.

range, 37-64 years) (Table 1). All patients in both groups had complete clinical and radiographic follow-up data 6 months following the surgery. There was no difference at baseline regarding their age $(\mathrm{P}=0.675)$, gender $(\mathrm{P}=0.327)$, BMI $(\mathrm{P}=0.090)$, level of planned corpectomy $(\mathrm{P}=0.700)$, JOA scores (13.40 \pm 2.39 vs. $12.35 \pm 2.48, \mathrm{P}=0.090)$, average $\mathrm{SF}-36$ scores (55.8 \pm 23.5 vs. $60.5 \pm 15.0, \mathrm{P}=0.771$ ), and cervical alignment

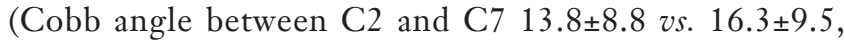

Wei et al. 3D-printed implant for anterior reconstruction in ACCF

Table 3 Clinical outcomes of the EBM-AVB group vs. the TMC group

\begin{tabular}{lccc}
\hline Clinical outcomes & EBM-AVB group & TMC group & P value \\
\hline JOA scores & & & \\
Pre-operative & $13.40 \pm 2.39$ & $12.35 \pm 2.48$ & 0.090 \\
6-month f/u & $16.35 \pm 0.93$ & $15.35 \pm 1.81$ & 0.019 \\
Recovery rate, $\%$ & $80.8 \pm 27.0$ & $69.1 \pm 25.1$ & 0.081 \\
SF-36 & & & \\
Pre-operative & $55.8 \pm 23.5$ & $60.5 \pm 15.0$ & 0.771 \\
6-month f/u & $66.3 \pm 18.2$ & $68.9 \pm 13.4$ & 0.695 \\
Odom's criteria & & & 0.716 \\
Excellent & 8 & 8 & \\
Good & 5 & 7 & \\
Fair & 7 & 5 & \\
\hline
\end{tabular}

EBM-AVB, electron beam melting-artificial vertebral body; TMC, titanium mesh cage.

$\mathrm{P}=0.196$ ) between the two groups (Tables 1-3). Patients in both groups all had normal bone mineral density (BMD).

\section{Radiological evaluation}

At 6 months post-operatively, successful fusion was observed in all cases in both groups with the exception of one patient in the TMC group whose radiological studies showed signs of screw loosening. However, the patient was asymptomatic and surgical revision was saved for a prolonged course of immobilization with a Philadelphia collar. No difference was detected between the two groups in regards to the rates of spinal fusion $(\mathrm{P}=0.995)$ (Table 2). Implant subsidence was statistically more significant in the TMC group than in the EBM-AVB group at the 6-month follow-up (mean loss of height $2.39 \pm 1.68 v s .1 .39 \pm 1.05 \mathrm{~mm}$, $\mathrm{P}=0.015$ ) (Table 2). Additionally, the percentage of severe subsidence in the TMC group was significantly higher than that in the EBM-AVB group ( $35 \%$ vs. $5 \%, \mathrm{P}=0.018$ ) (Table 2). No significant difference in global lordosis $(17.9 \pm 5.0$ vs. $20.4 \pm 8.5$ degrees, $\mathrm{P}=0.136$ ) was found between the two groups six months after the surgery (Table 2). Additionally, patients demonstrated a significant increase in global cervical lordosis in both the TMC group $(\mathrm{P}=0.022)$ and the AVB group $(\mathrm{P}<0.001)($ Table 4$)$. X-rays and CT scans of patients from both groups immediately post-operative and at the last follow-up were demonstrated in Figure 2. 

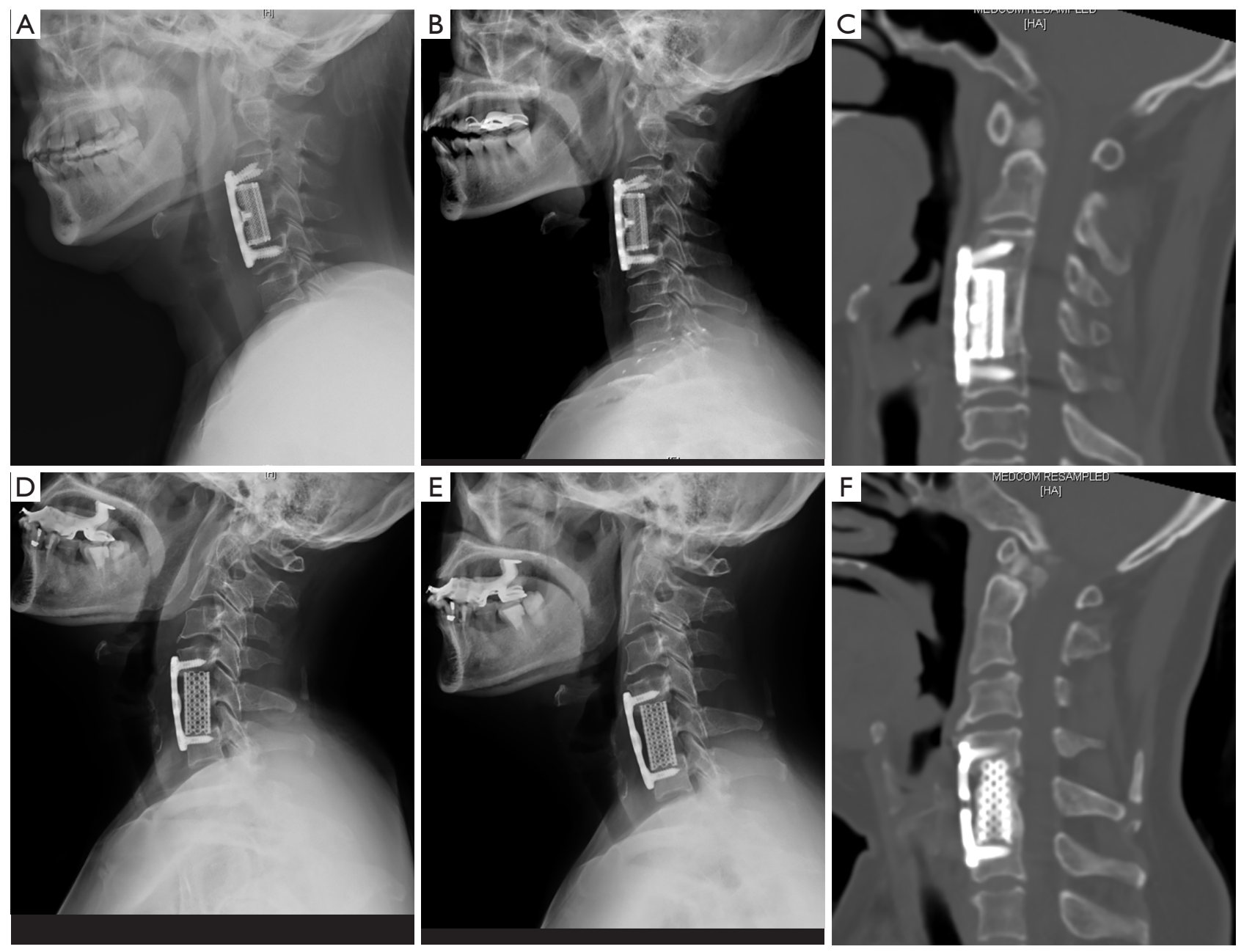

Figure 2 Illustrative cases of 2 patients from the AVB and the TMC group, respectively, with imaging studies at different clinical time points. (A) Immediate post-operative X-ray of a patient in the AVB group; (B) 6-month post-operative X-ray of a patient in the AVB group demonstrating minimal implant subsidence; (C) mid-sagittal reconstruction of CT at last follow-up of a patient in the AVB group demonstrating fusion with minimal implant subsidence; (D) immediate post-operative X-ray of a patient in the TMC group; (E) 6-month post-operative X-ray of a patient in the TMC group demonstrating implant subsidence; mid-sagittal reconstruction of CT at last follow-up of a patient in the TMC group demonstrating implant subsidence.

\section{Clinical results}

The course of post-operative recovery for all patients from both groups were uneventful with no revision procedures being scheduled. Patients' neurological function at the 6-month follow-up was significantly higher in the AVB group than in the TMC groups according to the JOA scale $(16.35 \pm 0.93$ vs. $15.35 \pm 1.81, \mathrm{P}=0.019)$ (Table 3). Both groups improved significantly after the surgery $(\mathrm{P}<0.001$ and $\mathrm{P}<0.001)$, but their JOA recovery rates were comparable $(80.8 \% \pm 27.0 \%$ vs. $69.1 \% \pm 25.1 \%, \mathrm{P}=0.081)$ (Table 4). Patients in the two groups had similar SF-36 scores at the last follow-up $(66.3 \pm 18.2$ vs. $68.9 \pm 13.4, \mathrm{P}=0.695)$ (Table 3) and improvement was significant for those in the AVB group ( $\mathrm{P}=0.009)$ but not for those in the TMC group $(\mathrm{P}=0.079)$ (Table 4). $65 \%$ of the patients in the AVB group and $75 \%$ in the TCM group were graded as excellent or good according to Odom's criteria, however, the difference was not statistically significant $(\mathrm{P}=0.716)$ (Table 4).

\section{Discussion}

Successful reconstruction of the anterior column following 


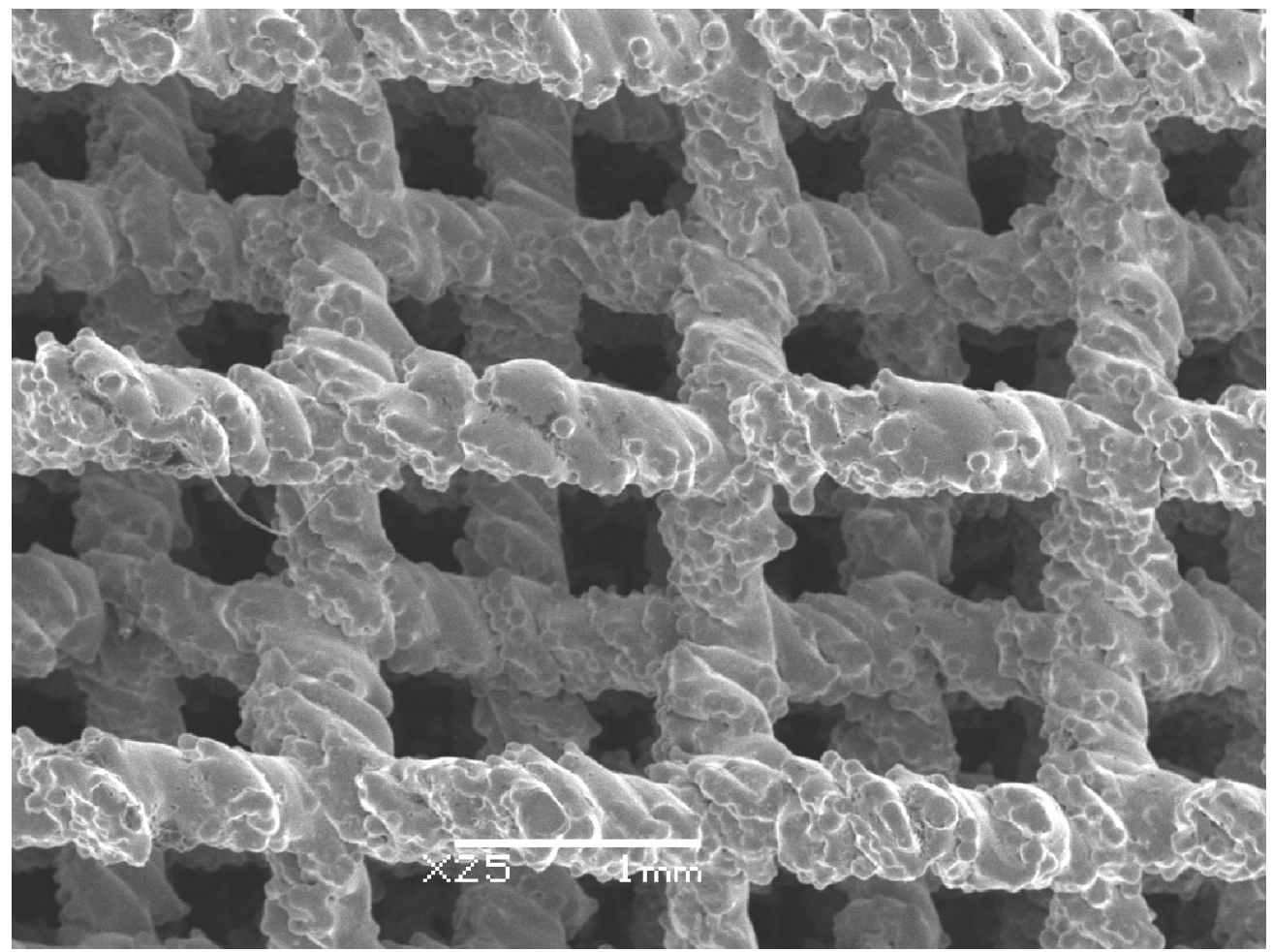

Figure 3 Microstructure detailing the roughed surface of the 3D-pritned AVB. AVB, artificial vertebral body.

Table 4 Pre-operative and post-operative comparison regarding JOA, VAS, SF-36 and C2-7 lordosis for the EBM-AVB group and the TMC group

\begin{tabular}{lccc}
\hline Group & Pre-operative & Post-operative P value \\
\hline EBM-AVB group & & & \\
JOA score & $13.40 \pm 2.39$ & $16.35 \pm 0.93$ & $<0.001$ \\
SF-36 & $55.8 \pm 23.5$ & $66.3 \pm 18.2$ & 0.009 \\
Global lordosis (C2-7) & $13.8 \pm 8.8$ & $17.9 \pm 5.0$ & $<0.001$ \\
TMC group & & & \\
JOA score & $12.35 \pm 2.48$ & $15.35 \pm 1.81$ & $<0.001$ \\
SF-36 & $60.5 \pm 15.0$ & $68.9 \pm 13.4$ & 0.079 \\
Global lordosis (C2-7) & $16.3 \pm 9.5$ & $20.4 \pm 8.5$ & 0.022 \\
\hline
\end{tabular}

EBM-AVB, electron beam melting-artificial vertebral body; TMC, titanium mesh cage.

ACCF is crucial for restoration of stability and alignment. Structural autograft can facilitate osteo-induction (due to bone morphogenetic proteins and other growth factors), osteo-genesis (induced by osteo-progenitor cells), and osteo-conduction (1) (through scaffolding effects), however, at the cost of donor-site complications. Alternatives, like TMC, while avoiding bone grafting, have been associated with implant subsidence $(9,33)$, and the stress shielding effect may hinder osseous fusion.

$3 \mathrm{D}$-printing technology is an additive manufacturing technique that can be used to manufacture titanium alloy implants with the desired shape and micro-structure. The roughened surface formed by the melted Ti6Al4V powder particles (Figure 3) facilitates cell adhesion and proliferation, both important steps for bone in-growth. In this study, EBM-AVB was not customized to the specific anatomy of each patient or each sub-axial cervical level. Since surgical skills like resection of the anterior osteophyte and endplate preparation were hard to standardize, the exact amount of space required by the tailor-made implants would be difficult to determine intra-operatively. Rather, our EBMAVB came in different sizes and the one fitting the postcorpectomy space the best was chosen during surgery. Additionally, the EBM-AVB, although not anatomical by design, was manufactured with a $4^{\circ}$ tilting angle at both ends to help restore the normal segmental cervical alignment while approximating the anatomical endplate slope at the same time (34). 
Both the EBM-AVB and the TMC groups achieved improvement in their neurological function, cervical lordosis, and health-related quality-of-life (HRQoL). Statistically significant difference was identified between the two groups regarding height loss of the fusion mass and the occurrence of severe subsidence. EBM-AVB was shown to effectively prevent implant subsidence and provide more stability than the conventional TMC. Although fusion rate was greater in the EBM-AVB group, future research with greater sample sizes is required to confirm whether the increased stability can be translated to higher fusion rates that are statistically meaningful. No difference in clinical outcomes was identified between the two groups, which was consistent with findings from previous studies since the short-term outcomes were primarily determined by the decompression techniques (35). During the study period, spinal fusion was observed in all but one patient. Once fusion was observed, the chance for further deterioration of implant subsidence would be low. Therefore, although a longer-term study would be more ideal theoretically, the follow-up period in this study might be just long enough to support our conclusions regarding decreased loss of height of the fusion mass and a lower rate for severe subsidence in the EBM-AVB group in comparison to the TMC group.

\section{Conclusions}

By the 6-month follow-up, SL-ACCF patients in the EBMAVB group demonstrated comparable clinical outcomes regarding improvement in neurological function and HRQoL to patients in the TMC group. However, the use of EBM-AVB was associated with decreased loss of height of the fusion mass and a lower rate for severe implant subsidence that was statistically significant.

\section{Acknowledgments}

Funding: This is study was supported by an intramural research fund of Peking University Third Hospital (Grant No. BYSY2017002) and a grant from Capital's Fund for Health Development and Research (Grant No. 2018-44097). The organizations that funded this study had no role in the study design, data collection and analysis or the decision to prepare or publish the manuscript.

\section{Footnote}

Reporting Checklist: The authors have completed the
CONSORT reporting checklist. Available at http://dx.doi. org/10.21037/atm-19-4719

Data Sharing Statement: Available at http://dx.doi. org/10.21037/atm-19-4719

Conflicts of Interest: All authors have completed the ICMJE uniform disclosure form (available at http://dx.doi. org/10.21037/atm-19-4719). NX serves as an unpaid Section Editor of Annals of Translational Medicine from Oct 2019 to Sep 2020. The authors have no other conflicts of interest to declare.

Ethical Statement: The authors are accountable for all aspects of the work in ensuring that questions related to the accuracy or integrity of any part of the work are appropriately investigated and resolved. This study was conducted in accordance with the Declaration of Helsinki (as revised in 2013). This prospective randomized open-label trial was under an investigational device exemption granted by local hospital ethics committee of Peking University Third Hospital (No. M2018206) and informed consent was taken from all participants regarding the aims and protocols of the study.

Open Access Statement: This is an Open Access article distributed in accordance with the Creative Commons Attribution-NonCommercial-NoDerivs 4.0 International License (CC BY-NC-ND 4.0), which permits the noncommercial replication and distribution of the article with the strict proviso that no changes or edits are made and the original work is properly cited (including links to both the formal publication through the relevant DOI and the license). See: https://creativecommons.org/licenses/by-nc-nd/4.0/.

\section{References}

1. Emery SE. Cervical spondylotic myelopathy: diagnosis and treatment. J Am Acad Orthop Surg 2001;9:376-88.

2. Lunsford LD, Bissonette DJ, Zorub DS. Anterior surgery for cervical disc disease. Part 2: Treatment of cervical spondylotic myelopathy in 32 cases. J Neurosurg 1980;53:12-9.

3. Cabraja M, Abbushi A, Koeppen D, et al. Comparison between anterior and posterior decompression with instrumentation for cervical spondylotic myelopathy: sagittal alignment and clinical outcome. Neurosurg Focus 2010;28:E15. 
4. Fehlings MG, Barry S, Kopjar B, et al. Anterior Versus Posterior Surgical Approaches to Treat Cervical Spondylotic Myelopathy: Outcomes of the Prospective Multicenter AOSpine North America CSM Study in 264 Patients. Spine (Phila Pa 1976) 2013;38:2247-52.

5. Hirai T, Okawa A, Arai Y, et al. Middle-term results of a prospective comparative study of anterior decompression with fusion and posterior decompression with laminoplasty for the treatment of cervical spondylotic myelopathy. Spine (Phila Pa 1976) 2011;36:1940-7.

6. Mohammad-Shahi MH, Nikolaou VS, Giannitsios D, et al. The effect of angular mismatch between vertebral endplate and vertebral body replacement endplate on implant subsidence. J Spinal Disord Tech 2013;26:268-73.

7. Nakase H, Park YS, Kimura H, et al. Complications and long-term follow-up results in titanium mesh cage reconstruction after cervical corpectomy. J Spinal Disord Tech 2006;19:353-7.

8. Das K, Couldwell WT, Sava G, et al. Use of cylindrical titanium mesh and locking plates in anterior cervical fusion. Technical note. J Neurosurg 2001;94:174-8.

9. Chen Y, Chen D, Guo Y, et al. Subsidence of titanium mesh cage: a study based on 300 cases. J Spinal Disord Tech 2008;21:489-92.

10. Kanayama M, Hashimoto T, Shigenobu K, et al. Pitfalls of anterior cervical fusion using titanium mesh and local autograft. J Spinal Disord Tech 2003;16:513-8.

11. Daubs MD. Early failures following cervical corpectomy reconstruction with titanium mesh cages and anterior plating. Spine (Phila Pa 1976) 2005;30:1402-6.

12. Hasegawa K, Abe M, Washio T, et al. An experimental study on the interface strength between titanium mesh cage and vertebra in reference to vertebral bone mineral density. Spine (Phila Pa 1976) 2001;26:957-63.

13. Dorai Z, Morgan H, Coimbra C. Titanium cage reconstruction after cervical corpectomy. J Neurosurg 2003;99:3-7.

14. Narotam PK, Pauley SM, McGinn GJ. Titanium mesh cages for cervical spine stabilization after corpectomy: a clinical and radiological study. J Neurosurg 2003;99:172-80.

15. Hee HT, Majd ME, Holt RT, et al. Complications of multilevel cervical corpectomies and reconstruction with titanium cages and anterior plating. J Spinal Disord Tech 2003;16:1-8; discussion 8-9.

16. Ferguson SJ, Weber U, von Rechenberg B, et al. Enhancing the mechanical integrity of the implant-bone interface with BoneWelding technology: determination of quasi-static interfacial strength and fatigue resistance. J
Biomed Mater Res B Appl Biomater 2006;77:13-20.

17. Edwards TR, Tevelen G, English H, et al. Stripping torque as a predictor of successful internal fracture fixation. ANZ J Surg 2005;75:1096-9.

18. Davis KG, Parnianpour M. Subject-specific compressive tolerance estimates. Technol Health Care 2003;11:183-93.

19. Schroder J, Herbort M, Rustemeyer P, et al. Mechanical response of cervical vertebral endplates to axial loading. Zentralbl Neurochir 2006;67:188-92.

20. Fourney DR, Gokaslan ZL. Spinal instability and deformity due to neoplastic conditions. Neurosurg Focus 2003;14:e8.

21. Yang J, Cai H, Lv J, et al. In vivo study of a self-stabilizing artificial vertebral body fabricated by electron beam melting. Spine (Phila Pa 1976) 2014;39:E486-92.

22. Yang J, Cai H, Lv J, et al. Biomechanical and histological evaluation of roughened surface titanium screws fabricated by electron beam melting. PLoS One 2014;9:e96179.

23. Zou X, Li H, Teng X, et al. Pedicle screw fixation enhances anterior lumbar interbody fusion with porous tantalum cages: an experimental study in pigs. Spine (Phila Pa 1976) 2005;30:E392-9.

24. Heinl P, Muller L, Korner C, et al. Cellular Ti-6Al-4V structures with interconnected macro porosity for bone implants fabricated by selective electron beam melting. Acta Biomater 2008;4:1536-44.

25. Bandyopadhyay A, Espana F, Balla VK, et al. Influence of porosity on mechanical properties and in vivo response of Ti6Al4V implants. Acta Biomater 2010;6:1640-8.

26. Fukuda A, Takemoto M, Saito T, et al. Osteoinduction of porous Ti implants with a channel structure fabricated by selective laser melting. Acta Biomater 2011;7:2327-36.

27. Chai YC, Kerckhofs G, Roberts SJ, et al. Ectopic bone formation by 3D porous calcium phosphate-Ti6Al4V hybrids produced by perfusion electrodeposition. Biomaterials 2012;33:4044-58.

28. Andaluz N, Zuccarello M, Kuntz C. Long-term followup of cervical radiographic sagittal spinal alignment after 1- and 2-level cervical corpectomy for the treatment of spondylosis of the subaxial cervical spine causing radiculomyelopathy or myelopathy: a retrospective study. J Neurosurg Spine 2012;16:2-7.

29. Mummaneni PV, Burkus JK, Haid RW, et al. Clinical and radiographic analysis of cervical disc arthroplasty compared with allograft fusion: a randomized controlled clinical trial. J Neurosurg Spine 2007;6:198-209.

30. Liu Y, Qi M, Chen H, et al. Comparative analysis of complications of different reconstructive techniques 
following anterior decompression for multilevel cervical spondylotic myelopathy. Eur Spine J 2012;21:2428-35.

31. Hirabayashi K, Watanabe K, Wakano K, et al. Expansive open-door laminoplasty for cervical spinal stenotic myelopathy. Spine (Phila Pa 1976) 1983;8:693-9.

32. Odom GL, Finney W, Woodhall B. Cervical disk lesions. J Am Med Assoc 1958;166:23-8.

33. Lau D, Song Y, Guan Z, et al. Radiological outcomes of static vs expandable titanium cages after corpectomy: a

Cite this article as: Wei F, Xu N, Li Z, Cai H, Zhou F, Yang J, Yu M, Liu X, Sun Y, Zhang K, Pan S, Wu F, Liu Z. A prospective randomized cohort study on 3D-printed artificial vertebral body in single-level anterior cervical corpectomy for cervical spondylotic myelopathy. Ann Transl Med 2020;8(17):1070. doi: 10.21037/atm-19-4719 retrospective cohort analysis of subsidence. Neurosurgery 2013;72:529-39; discussion 538-9.

34. Chen H, Zhong J, Tan J, et al. Sagittal geometry of the middle and lower cervical endplates. Eur Spine J 2013;22:1570-5.

35. Fengbin Y, Jinhao M, Xinyuan L, et al. Evaluation of a new type of titanium mesh cage versus the traditional titanium mesh cage for single-level, anterior cervical corpectomy and fusion. Eur Spine J 2013;22:2891-6. 